\title{
O processo de construção do lugar e da identidade dos moradores de uma cidade reinventada
}

\author{
Ada Raquel Teixeira Mourão \\ Sylvia Cavalcante \\ Universidade de Fortaleza
}

\begin{abstract}
Resumo
O estudo buscou conhecer a identidade de lugar dos moradores de Maracanaú, cidade localizada na Região Metropolitana de Fortaleza, que passou por um processo induzido de industrialização e urbanização que a transformou de localidade rural em espaço urbano. A pesquisa se deu junto a três grupos de pessoas: os moradores originais, que se encontravam na cidade antes da sua transformação; os moradores dos conjuntos habitacionais, que vivenciaram o processo de transformação; e os jovens, que não participaram dos momentos anteriores e se relacionam com a cidade como ela é hoje. A análise da relação dos sujeitos com o espaço habitado permitiu distinguir diversas formas de ligação com a cidade. Os resultados apontaram para a construção de uma nova e múltipla identidade de lugar, assentada em pontos comuns como a valorização de símbolos do passado, participação na vida cotidiana e nas festividades da cidade e expectativas positivas quanto ao futuro.
\end{abstract}

Palavras-chave: identidade; psicologia ambiental; desenvolvimento urbano

\begin{abstract}
The construction process of place and identity of inhabitants of a "reinvented" city. The study aimed to find out about the place-identity of the inhabitants of Maracanaú, a city located in the metropolitan region of Fortaleza, which went through an induced process of industrialization and urbanization which transformed the rural local into urban space. Three groups of people were approached and questioned: original inhabitants, who were in the city before its transformation; the inhabitants of housing developments who went through the transformation process; and youth who did not go through these earlier moments and relate to the city as it is today. The analysis of the relationship of those persons with the inhabited space allowed us to distinguish various forms of connection with the city. The results point to the construction of a new and multiple placeidentity, set on common points such as giving value to symbols of the past, participating in daily life and in the festivals of the city as well as having positive expectations for the future.
\end{abstract}

Keywords: identity; environmental psychology; urban development

$\mathrm{O}$ crescimento exacerbado das cidades vem gerando situações curiosas, entre as quais citaríamos a ocupação do espaço das regiões vizinhas, promovendo transformações que pouco se relacionam com o estilo de vida ou a vocação original das cidades ocupadas.

Desse fato constatam-se alguns aspectos: o primeiro e mais perceptível, porque se reflete na constituição física das cidades, é a conurbação ou a falta de limites entre as cidades, devendo o visitante estar atento a símbolos ou mesmo cartazes que expressem a mudança de território administrativo. O segundo, e o aspecto mais preocupante, se refere à utilização dos espaços de cidades vizinhas, secundárias e muitas vezes dependentes das cidades centrais, servindo como área de instalação dos seus restos urbanos, aquilo que polui ou degrada seu ambiente físico e social. Estas transformações de espaços não possuem somente conseqüências físicas, elas modificam igualmente o tecido social, o que gera uma nova conformação da relação homem-entorno vivido.

Assim se passou com Maracanaú, situada na região metropolitana de Fortaleza, Estado do Ceará-Brasil. Em duas décadas - de 1970 a 1990 -, transformou-se de cidadezinha com aspecto rural e uma população com cerca de 15 mil habitantes em cidade industrial, através da implantação de distritos industriais, passando a contar com uma população recém-instalada e sem vínculos com o lugar, em torno de 157 mil habitantes que vieram se fixar como moradores nos diversos mega- 
conjuntos habitacionais implantados em seu território. Esta intervenção ambiental refletiu uma escolha econômica, urbanística, política e social.

A escolha econômica inaugurou, na década de 1970, a entrada de um estado nordestino, pobre, vítima de secas sazonais, capturado por uma oligarquia agrária (Oliveira, 1977) e com pouca tradição industrial, em um período de incentivo ao investimento industrial como estratégia de crescimento. Tal mudança de rumos ocorreu impulsionada pelas grandes disparidades econômicas regionais entre um sul-sudeste desenvolvido e industrial e um norte-nordeste subdesenvolvido e rural. O Estado do Ceará passou a fazer parte de uma estratégia nacional de industrialização que tinha como meta a instalação de distritos industriais em regiões periféricas. As zonas industriais seriam implantadas longe dos centros urbanos e preparadas infra-estruturalmente para receber uma grande quantidade de indústrias. Dentro desse contexto, os estudos realizados apontavam para a instalação do Distrito Industrial de Fortaleza em uma área atualmente pertencente à cidade de Maracanaú que, na ocasião, era distrito de Maranguape. Foi implantado, então, por decreto governamental, o I Distrito Industrial, sendo seguido, alguns anos mais tarde, pela instalação de mais dois.

Entretanto, outros aspectos contribuíram para a transformação física e social do território de Maracanaú. Através da via urbanística, procurava-se encontrar solução para o problema do crescimento de Fortaleza, ocorrido a partir dos anos 1950, quando se iniciou um forte processo de migração rural. A construção de grandes conjuntos habitacionais ligados ao distrito industrial, fora da área urbana, tinha como objetivo solucionar vários problemas: prover moradia para a população pobre e a mão-de-obra para as indústrias, além de liberar grandes espaços urbanos. A idéia da retirada de uma grande parcela da população pobre para fora dos centros urbanos, como estratégia de limpeza de espaços nobres, pode ser igualmente associada à estratégia ideológica dos governos militares que tinha como lema promover "o sonho da casa própria”.

Maracanaú é hoje uma cidade que beira os 200 mil habitantes, possui oito grandes conjuntos habitacionais, constituídos por cerca de 15 mil unidades habitacionais, e três distritos industriais com mais de 100 indústrias instaladas, algumas fortemente poluentes, tudo isso numa área que não ultrapassa os $98 \mathrm{~km}^{2}$. Apesar de se tornar um vigoroso distrito industrial, grande parte dos empregos ali gerados não beneficiaram os moradores instalados nos conjuntos. Até recentemente, somente cerca de $6 \%$ dos habitantes da cidade trabalhavam no distrito industrial. Durante longos anos, a cidade ficou conhecida como cidade-dormitório, devido à sua desertificação durante o dia. A partir do crescimento populacional, surgiu a necessidade de implantação de um forte setor de serviços, que mais recentemente se completou com a instalação de um shopping center no principal conjunto habitacional e próximo ao centro da cidade. Deste modo, Maracanaú foi transformada de localidade rural em espaço urbano, onde convive uma diversidade de moradores que chegaram da capital ou do interior, principalmente atraídos pela possibilidade de ali adquirirem a "casa própria”.

A mudança em seu espaço físico e suas inter-relações com aspectos individuais e sociais determinou novas dinâmicas ao entorno. Populações de moradores originais - aqueles que já se encontravam no território antes da intervenção e moradores dos conjuntos passaram a habitar a mesma cidade. Uma cidade inventada por decreto governamental que, porém, vem a cada dia sendo reconstruída e reinventada por seus novos e antigos moradores. Metamorfoseada em depositária dos resultados do processo de expansão de Fortaleza, hoje, mais de vinte anos depois, Maracanaú está construindo, através de seus diferentes moradores, uma alma própria, baseada em processos singulares de apropriação desse espaço, transformando-se num verdadeiro lugar pleno de significados, que influi decisivamente sobre a construção da identidade de seus habitantes.

\section{Tema fundamental de investigação: uma cidade sem identidade}

Maracanaú apresentava-se como uma incógnita. Aos olhos de um observador desatento, uma cidade tão desfigurada em relação ao seu aspecto inicial de localidade interiorana poderia parecer somente um amontoado de pessoas vivendo juntas num mesmo espaço.

Com relação ao seu aspecto físico, percebia-se rapidamente, por meio de uma visita ao centro da cidade e ao seu maior conjunto habitacional, o Conjunto Jereissati, a imagem de uma cidade claramente fragmentada. Um centro com aspecto de cidade interiorana, com pracinha, igreja matriz, banco e pequenos pontos comerciais, circundado por casas com aspecto antigo, e a zona vizinha a este centro e quase se misturando a ele - o Conjunto Jereissati -, com ruas e avenidas numeradas, casas em estilo padronizado, adaptadas desordenadamente por seus moradores, invadindo calçadas e com poças de água escorrendo pelas coxias. Em suma, a antiestética urbana.

No seu aspecto social, a cidade apresentava-se também dividida. A divisão era expressa pela frase dita por alguns de seus moradores quando se definiam: "existem os moradores de um lado e os moradores do outro lado”. A expressão refere-se à linha imaginária que separa a cidade antiga dos conjuntos habitacionais e que reflete, também, a divisão social entre os moradores dos conjuntos dos moradores originais.

Outro aspecto importante para a definição do tema de investigação foi a afirmação, constantemente repetida por parte dos técnicos da Prefeitura Municipal, de que "a cidade não possui identidade”. Segundo esses técnicos, os moradores dos conjuntos, em sua grande maioria provenientes de outros municípios, usariam a cidade como dormitório já que, pela proximidade da capital, grande parte lá trabalharia. Para confirmar sua afirmação, os técnicos apontavam a dificuldade em realizar um trabalho social participativo pela falta de envolvimento dos moradores com os problemas da cidade.

A partir da realidade percebida no entorno, a pergunta formulada inicialmente foi: os moradores de Maracanaú pos- 
suem identidade de lugar? Entretanto, como veremos adiante, o conceito de identidade de lugar respondia a uma parte dos questionamentos, sendo mais relacionado aos aspectos individuais. Foi necessário, portanto, buscar apoio em abordagens teóricas que levassem em conta igualmente os aspectos sociais associados aos espaciais, o que se fez através do conceito de identidade social urbana.

\section{As lentes através das quais se vê o problema: revisão dos conceitos teóricos}

\section{Psicologia Ambiental: o campo teórico mais amplo}

$\mathrm{O}$ estudo da identidade associada a um espaço físico e social insere-se no campo teórico da Psicologia Ambiental. De fato, segundo Moser (2003), a "Psicologia Ambiental é o estudo das inter-relações entre o indivíduo e seu entorno físico e social, dentro de suas dimensões espaciais e temporais” (p. 16). Neste sentido, um estudo que leva em conta o ambiente vivido volta um olhar especial sobre o indivíduo que o vivencia e as transformações que podem ocorrer nele a partir das mudanças no espaço, sem perder de vista o aspecto temporal, que é fundamental para qualquer processo de transformação.

O objetivo de um estudo em Psicologia Ambiental seria, portanto, identificar os processos que regulam e intermedeiam a relação homem-entorno, evidenciando, de uma parte, as percepções, atitudes, avaliações e representações ambientais, e de outra parte, os comportamentos do sujeito (Moser, 2003). Este estudo se passa, portanto, em dois níveis, um mais primário, que se refere à ação e transformação que o sujeito sente que pode realizar em seu entorno, outro mais elaborado, ou simbólico, que se refere aos processos de identificação constituídos com este entorno (Pol, 1996).

\section{Apropriação: a significação do espaço}

Um processo essencial para que alguém se sinta identificado ou pertencente a um entorno é o que se entende por apropriação. Na apropriação, o sujeito interage dialeticamente com o entorno, o que resulta numa transformação mútua.

Para Fischer (1981), na relação homem/meio, existe uma prática espacial que se dá por meio de condutas que modificam o espaço e inserem o ser humano no meio. Essa inserção não é, entretanto, unilateral. O sujeito age sobre o meio, modifica-o e, neste processo, vai deixando sua marca e sendo igualmente marcado por ele. Isto se dá na medida em que as transformações do meio pelo homem são resultantes de necessidades subjetivas, de emoções, de expectativas, em suma, de vivências que vão fazendo parte da história pessoal do sujeito.

As ações sobre o espaço não se constituem, portanto, somente em atos cognitivos ou materiais, mas em atos de investimento emocional, momento em que o agir e o sentir encontram-se em plena sintonia.

Segundo Pol (1996), a criação e o surgimento de um universo de significados que constituem a cultura e o entorno do sujeito e que transformam, ao longo do tempo, um espaço vazio em lugar significativo é o que se pode chamar de apropriação. Pela apropriação, o sujeito sente que de alguma forma está ligado ao lugar, e que este lhe pertence, mesmo que dele não tenha a posse legal. A relação vem a ser recíproca, pois ele também pertence ao lugar.

A apropriação, relacionada ao espaço, é o mecanismo que permite ao sujeito sentir que tem o domínio de um lugar, que pode arrumá-lo, reestruturá-lo, construindo ali algo com o qual se identifique, um chez soi, ou seja, o seu lugar (Fischer, 1981). A apropriação pode, portanto, ser entendida como uma necessidade humana de enraizamento (Moles \& Rohmer, 1998), que ocorre quando o eu se inscreve num lugar geográfico e, a partir daí, há o que se chama de criação do point ici, quando um ponto, ou espaço indefinido passa a ser importante para o sujeito que o vivencia. É uma busca de segurança através da ligação com o lugar. Pol (1996) afirma que:

\footnotetext{
As pessoas, individualmente ou de forma coletiva, necessitam identificar territórios como próprios, para construir sua personalidade, estruturar suas cognições e suas relações sociais, e ao mesmo tempo suprir suas necessidades de pertença e de identificação. (p. 50)
}

A relação sujeito-meio ambiente é inevitável, o que pode variar é a forma dessa interação, que pode ser influenciada por fatores como local de moradia, tempo de contato com o lugar, idade, sexo, etc., o que será tratado mais adiante através da exposição dos resultados. Fischer (1981) explica que é da familiaridade com o espaço que nasce a apropriação e que ela é construída e reconstruída ao longo do tempo como resultado de um processo dialético.

Esse processo de pertencimento e apropriação associado a um lugar é formador da identidade dos sujeitos (grifos nossos), tanto quanto suas relações familiares e sociais.

\section{Identidade: construção e metamorfose}

Como poderíamos melhor definir cada um de nós? O conceito de identidade é, muitas vezes, explicitado através das formas como o sujeito é e está no mundo. O ser humano pode fazer várias perguntas e levar em conta vários aspectos relacionados à construção de si mesmo.

A construção da identidade é um processo complexo que se passa em vários níveis e, portanto, um só aspecto seria insuficiente para expressar sua totalidade. Por ser um processo múltiplo se expressa através de diversos sistemas identificadores. Jacques (1998) explica:

\footnotetext{
Os sistemas identificatórios são subdivididos e a identidade passa a ser qualificada como identidade pessoal (atributos específicos do indivíduo) e/ou identidade social (atributos que assinalam a pertença a grupos ou categorias); essa última ainda recebe predicativos mais específicos como identidade étnica, religiosa, profissional, etc. (p. 161)
}

A multiplicidade da identidade comporta vários sistemas identificatórios e compreende um processo dinâmico e mutável.

Sève (1989) defende que o homem tem como suporte a individualidade biológica que lhe dá, tanto condições gerais 
de possibilidade próprias de sua espécie, como condições particulares de realidade, advindas de sua carga genética. Entretanto, o que caracteriza sua humanidade são as capacidades historicamente adquiridas, que se evidenciam no mundo social e das quais ele se apropria, através de suas relações, no desenrolar de sua existência.

A apropriação destaca o caráter ativo deste processo. O ser humano não simplesmente se adapta ou introjeta o ambiente, mas ele se apropria ou não, conforme sua individualidade e aquilo que the é oferecido ou dado como possibilidade, dentro do seu contexto histórico e social. Através da apropriação, o ser humano dialoga com o ambiente e sua identidade vai se construindo ao mesmo tempo em que ele contribui para a construção ativa do contexto. Esse processo de construção recíproca, Sève (1989) resume, na seguinte frase: "o que um homem faz de sua vida e o que a sua vida faz dele" (p. 156).

Ciampa (1988) utiliza a linguagem dramática para explicar como o sujeito constrói a si mesmo, sua identidade. À construção da identidade Ciampa (1988) atribui um caráter estável e ao mesmo tempo processual; para o autor, identidade é descrita como um processo de metamorfose. O sujeito é, portanto, o resultado da sucessão e coexistência de diversos personagens criados por ele mesmo ao longo da vida. A identidade é um produto da história desses personagens, de suas vidas e suas mortes, numa processualidade e transformação.

\section{A identidade aplicada ao entorno físico e social}

O conceito de identidade, aqui explicitado, considera que o homem se constitui no meio e através deste. Portanto, pode ser localizado nos estudos de identidade social. Tajfel (1981, citado por Valera \& Pol, 1994) propõe que identidade social é "aquela parte do auto-conceito de um indivíduo derivada do conhecimento do seu pertencimento a um grupo ou grupos sociais juntamente com o significado valorativo e emocional associado a este pertencimento" (p. 8).

Nesse sentido, o entorno físico e social vivenciado pelo sujeito pode significar um componente fundamental para a construção da sua identidade. Mesmo que o entorno não seja considerado em muitos estudos de Psicologia Social, está claro que sua importância na constituição da identidade é cada vez mais aceita e estudada. Vários termos têm sido propostos, mas, de um modo geral, poder-se-ia aplicar o termo identidade social espacial (Valera \& Pol, 1994). Entretanto, os referenciais teóricos que mais interessam nesta discussão são os relacionados ao conceito de identidade de lugar (Proshansky; Fabian, \& Kaminof, 1983) e identidade social urbana (Valera \& Pol, 1994).

Segundo Proshansky et al. (1983), identidade de lugar é uma subestrutura da identidade profunda da pessoa e é constituída por cognições sobre o mundo físico, relativas à variedade e complexidade dos lugares nos quais ela vive e satisfaz suas necessidades biológicas, psicológicas, sociais e culturais.

As cognições são formadas pelas memórias, idéias, sentimentos, atitudes, valores, preferências, significados relacionados com o ambiente e que formam o que Proshansky et al. (1983) chamam de passado ambiental de uma pessoa. Os vínculos emocionais com o entorno são igualmente importantes na formação da identidade de lugar do sujeito. Esse aspecto é ressaltado por Tuan (1983), quando destaca a diferença entre as noções de espaço e lugar. Para o autor, lugar está relacionado a segurança e estabilidade, e espaço a liberdade e movimento. $\mathrm{O}$ espaço indiferenciado, caracterizado como o local da aventura, da liberdade e do movimento, transforma-se em lugar à medida que o sujeito o vivencia através do tempo e da intensidade, passando, então, a ser dotado de valor afetivo para o sujeito.

Proshansky et al. (1983) destacam, igualmente, o aspecto instável da identidade de lugar. Os cenários físicos mudam na sua capacidade de satisfazer necessidades e desejos, ou seja, o ideal interno de cenário físico do sujeito muda com o seu ciclo de vida; da mesma forma, o ambiente externo também se modifica, exigindo do sujeito um novo esforço de apropriação, o que propicia uma nova transformação na sua identidade.

Por outro lado, dentro de uma perspectiva mais coletiva, a definição do indivíduo dentro da sociedade passa por processos de categorização social. Assim, "a teoria da categorização do self de Turner contempla e amplia a teoria de Tajfel e dá ao tema da identidade social um enfoque mais grupal que individual" (Valera \& Pol, 1994, p. 10). A identidade social é construída não somente no grupo como algo que o indivíduo recolhe do grupo para si, mas é formada principalmente através do sentimento de pertencimento do sujeito a um grupo social.

Valera \& Pol (1994) ampliam o sentido de grupo social ao entorno físico quando afirmam que "o sentido de pertença a determinadas categorias sociais inclui também o sentido de pertença a determinados entornos urbanos significativos para o grupo" (pp. 10-11). E, ainda, que "os conteúdos dessas categorizações são determinados pela interação simbólica que se dá entre as pessoas que compartem um determinado espaço e que se identificam com ele através de um conjunto de significados socialmente elaborados e compartidos” (p. 11). Estas idéias constituem a base da identidade social urbana, que considera e integra a compreensão dos vários conceitos como os de: identidade de lugar, que contempla a construção da identidade do sujeito relacionada a aspectos mais individuais; identidade social, que leva em conta a importância do grupo ou dos aspectos sociais na constituição da identidade; teoria da categorização social, quando o entorno pode ser considerado uma categoria social através da qual o sujeito se define; identidade urbana, quando explica que este entorno significativo pode ser um espaço urbano (Lalli, 1988, citado por Valera \& Pol, 1994) e comunidade simbólica, através da qual se compreende que o espaço vivido é definido por meio de processos de simbolização, ou construção de significados associados ao espaço, e realizado dentro da interação social (Hunter, 1987, citado por Moreno \& Pol, 1999).

O termo identidade de lugar, embora limitado a aspectos individuais, é aqui utilizado levando-se em conta sua correlação com os conceitos e dimensões da identidade social urbana, que serão posteriormente tratados.

É, portanto, sob essa perspectiva teórica que se desenvolve o estudo da identidade de lugar em Maracanaú. 


\section{A construção metodológica}

A objetivo inicial desta pesquisa era conhecer a identidade de lugar dos moradores de Maracanaú por meio de um estudo de campo.

Ir a campo significou, no contexto da presente pesquisa, perder parcialmente a condição de quem vê de fora a vida cotidiana dos moradores e, a partir daí, faz inferências a respeito do que eles podem pensar e sentir com relação à cidade; significou entrar no universo de significados dos sujeitos, buscando a empatia. É o que em Etnologia chama-se observação participante, pois o pesquisador busca uma forte interação com a situação estudada. O contato com os colaboradores se deu em suas residências, locais de trabalho ou de vivências coletivas.

Além da observação participante, por meio das idas a campo, foram pesquisadas outras fontes como poemas, letras de música, expressões da subjetividade dos seus moradores, na tentativa de compreender a construção da significação deste lugar.

O estudo da identidade por si só é um tema complexo que envolve muitas variáveis. Apesar das várias ramificações deste estudo, entretanto, seu objetivo foi focalizado no entendimento dos aspectos relacionados à apropriação do espaço e sua transformação em lugar significativo; e no modo como se dá essa apropriação entre os diversos grupos de moradores, explicados a seguir, e aqui classificados como originais, dos conjuntos e jovens, buscando descobrir divergências e semelhanças que pudessem esclarecer sobre a construção da subjetividade desses moradores à luz, principalmente, dos conceitos de identidade de lugar e identidade social urbana.

A classificação dos sujeitos pesquisados em três grupos distintos surgiu da necessidade de compreender o fenômeno da identidade de lugar a partir da sua relação com os fatos marcantes para a transformação da localidade em cidade: a implantação do I Distrito Industrial de Fortaleza e a construção dos conjuntos habitacionais. Isto leva também a tentar captar o fenômeno dentro de uma perspectiva temporal: (1) antes da transformação (moradores originais), (2) no momento da transformação (moradores dos conjuntos) e (3) no momento presente (jovens). Dentro da categoria moradores dos conjuntos, a escolha recaiu sobre os moradores do Conjunto Jereissati, por ser o maior e mais significativo conjunto de Maracanaú. Tanto que, numa entrevista, uma moradora original acusou o Jereissati de ter "roubado" a identidade de Maracanaú. De fato, o Conjunto Jereissati, além de ser o maior, é o mais conhecido fora da cidade, o que lhe confere, por assim dizer, uma "forte personalidade". Ele é, também, o conjunto limítrofe com o centro histórico de Maracanaú, e que dele poderia receber, portanto, maiores influências. E se, mesmo assim, ele possui, como afirmam alguns moradores, uma identidade própria, ele pode muito bem ser representativo dos demais conjuntos. A intenção aqui não é de fazer generalizações, entretanto, a escolha se apóia na crença de que os dados coletados no Jereissati podem representar esse grupo de moradores, considerado, por muitos, como sem ligação com a cidade.

Buscando compreender o universo de significações desses três grupos de moradores, foram utilizados os diversos instrumentos de pesquisa explicitados a seguir.

\section{Entrevistas}

As entrevistas foram utilizadas como técnica de coleta de dados para os moradores originais e os moradores dos conjuntos, num total de cinco para cada categoria. Foram realizadas com base num roteiro previamente preparado, porém transcorreram como uma "conversa", em que os entrevistados expunham livremente suas idéias, embora sutilmente conduzidos, com base no roteiro, de forma a não fugir do tema. Os relatos foram gravados em áudio, depois de solicitada a permissão e assegurado o sigilo quanto à divulgação dos nomes reais dos entrevistados. Os entrevistados foram verdadeiros colaboradores, falaram com ânimo de suas vidas, das transformações ocorridas na cidade e dos seus projetos futuros.

\section{Mapas cognitivos}

A técnica dos mapas cognitivos ou mapas mentais foi utilizada como forma de complementar as informações obtidas através das entrevistas.

Os moradores do Conjunto Jereissati entrevistados foram solicitados a desenharem Maracanaú, identificando os seus marcos principais e procurando descrever as histórias e emoções ligadas a esses marcos. Dois não chegaram a desenhar: um deles porque foi entrevistado num local coletivo, onde não havia lugar para apoiar o papel, e a outra, uma senhora de idade, se disse sem condições de executar a tarefa. Apesar de poucos, os três mapas obtidos forneceram informações importantes sobre a imagem de Maracanaú para esses moradores do Conjunto Jereissati.

\section{Questionários}

Foram aplicados a um total de 268 jovens, ao longo de cinco Fóruns da Juventude promovidos pela Prefeitura Municipal, durante o segundo semestre de 2002. Os fóruns foram concebidos como espaço de discussão sobre os problemas que afetavam a juventude da cidade. A técnica foi utilizada pretendendo atingir um grande número de sujeitos e devido ao pouco tempo que restava para a conclusão do período da pesquisa.

Os jovens convidados eram ligados a alguma organização, instituição ou associação de bairro, associações religiosas, de esporte, de cultura ou grêmios estudantis. Tendo em vista a necessidade de atingir o município como um todo, a comissão organizadora dos fóruns convidou jovens oriundos de todos os bairros; o tempo de moradia não foi relevante como critério na escolha dos convidados. A faixa etária também foi definida entre 14 e 25 anos.

Durante esses encontros, no momento do cadastramento, eles preenchiam a "Ficha de participante", elaborada pelo comitê gestor do programa e na qual estavam contidas per- 
guntas úteis para o planejamento dos encontros e para o maior conhecimento do público-alvo do programa. Ao final da ficha, havia três questões sobre a relação do jovem com a cidade, que foram utilizadas para esta pesquisa: (1) "O que é Maracanaú para você?”; (2) "Você se sente maracanauense? Por quê?”; (3) "Você gosta de Maracanaú? Por quê?”.

Além dessa enquête, durante o segundo Fórum, do qual participaram 56 jovens, eles foram solicitados a apontar qual seria o "melhor cartão postal de Maracanaú". As respostas forneceram indícios sobre a representatividade de alguns lugares da cidade.

As respostas descritivas foram muito ricas em informações e significados. Por este motivo, apesar de privilegiar as entrevistas como instrumento de coleta de dados, foi importante incluir os dados fornecidos através dos questionários, tendo em vista a sua grande qualidade e quantidade.

Apesar da grande quantidade de respostas obtidas (268), os dados não foram tratados estatisticamente. A ênfase recaiu, portanto, sobre a análise qualitativa das respostas às questões.

\section{Análise documental}

Compreender as relações que se estabelecem entre os moradores e um lugar requer, necessariamente, a compreensão do lugar, da sua história e das motivações importantes para a sua transformação.

Nesse sentido, a análise de documentos foi fundamental para o esclarecimento sobre o modelo de desenvolvimento local proposto para o Estado do Ceará, como também as razões que levaram à escolha de Maracanaú como sede do Distrito Industrial de Fortaleza e local da implantação de diversos conjuntos habitacionais. Foram analisados documentos de planejamento dos diversos governos estaduais entre 1964 e 1983, documentos elaborados pelo Sindicato das Indústrias, através do Instituto Euvaldo Lodi (1983), e um estu- do de impacto elaborado por alunos do Centro de Treinamento e Desenvolvimento Regional (1984), durante o ano em que Maracanaú obteve a sua emancipação, em 1983. Todos estes documentos retratam uma visão da época e fornecem vias diversas de compreensão para o problema.

\section{Fotografias}

As imagens obtidas através de fotografias possuíam um caráter ilustrativo e auxiliaram na interpretação dos dados. Não foram realizadas fotos dos entrevistados, tendo em vista a preocupação em mantê-los no anonimato.

\section{Resultados e Discussão}

A partir das técnicas de coleta de dados empregadas, os dados encontrados foram analisados qualitativamente e classificados por grupo de morador, tendo em vista a perspectiva temporal de transformação da cidade e da evolução do processo de apropriação dos seus moradores no tempo. As categorias de análise apresentaram os resultados sintetizados na Figura 1.

O estudo das relações dos diversos moradores de Maracanaú com seu espaço de vida aponta para a constituição de diferentes processos de apropriação.

O grupo de moradores originais baseia seu processo de apropriação em aspectos relacionados à sua memória coletiva. Os moradores relatam sua história pessoal vivida e relacionada a um lugar determinado: Maracanaú. História que deixou marcas e que foi e segue sendo construída por um grupo coeso de moradores que viveram experiências semelhantes. Para Halbwachs (1990), tal história seria mais propriamente chamada de memória coletiva, posto que, de alguma forma, ainda vive na consciência do grupo.

De fato, a cidade de Maracanaú, antes de sofrer a atual intervenção, era uma pequena localidade, constituída por um

\begin{tabular}{|c|c|c|c|}
\hline \multicolumn{4}{|l|}{ Tempo } \\
\hline & Cidade de antes & Cidade em transformação & Cidade reinventada \\
\hline & Moradores originais & Moradores dos conjuntos & Moradores jovens \\
\hline & $\begin{array}{c}\text { Forte processo de coesão grupal e } \\
\text { constituição de uma memória } \\
\text { coletiva }\end{array}$ & $\begin{array}{c}\text { Enraizamento através da aquisição } \\
\text { da casa }\end{array}$ & $\begin{array}{c}\text { Identificação simbólica com a } \\
\text { cidade: ligação afetiva, construção } \\
\text { de laços de amizade e crescimento } \\
\text { pessoal associado ao lugar }\end{array}$ \\
\hline & $\begin{array}{l}\text { Participação ativa na vida cotidiana } \\
\text { e poder político }\end{array}$ & $\begin{array}{l}\text { Expansão de contatos sociais e de } \\
\text { vida cotidiana além dos muros da } \\
\text { casa }\end{array}$ & $\begin{array}{l}\text { Ação- transformação: inserção em } \\
\text { processos de participação cidadã }\end{array}$ \\
\hline & $\begin{array}{l}\text { Crença no futuro amparada na } \\
\text { melhoria da qualidade de vida e } \\
\text { superação do mal estar de ser uma } \\
\text { cidade estigmatizada }\end{array}$ & $\begin{array}{c}\text { Crença no futuro da cidade, na } \\
\text { melhoria da qualidade de vida na } \\
\text { cidade e expectativas de valoriza- } \\
\text { ção do preço da casa }\end{array}$ & $\begin{array}{c}\text { Crença no futuro da cidade e deles } \\
\text { próprios na cidade }\end{array}$ \\
\hline
\end{tabular}

Figura 1. Classificação dos grupos de moradores e principais características de suas relações com a cidade. 
grupo de moradores, com fortes relações de amizade e vizinhança. Durante as entrevistas, descrevem com alegria e forte nostalgia suas festas religiosas e vivências cotidianas, como banhos de lagoas, jogos de futebol e toda sorte de interações sociais vivenciadas, proporcionadas por espaço de convivência com poucos habitantes. Outro aspecto que contribuía para a coesão grupal era o relativo isolamento em que viviam, devido à falta de um bom serviço de transporte que comunicasse aquele distrito a Fortaleza e à sede municipal de então, Maranguape. Somente o trem fazia esta ligação, pela manhã, indo para a capital e à tarde voltando. $\mathrm{O}$ isolamento era também resultado do estigma que sofria a localidade devido à instalação, nas décadas de 1940 e 1950, de dois hospitais que tratavam enfermidades ainda sem cura: a hanseníase e a tuberculose. Seus moradores sentiam-se igualmente vítimas de descaso administrativo. Maranguape não destinava recursos à melhoria dos serviços públicos em Maracanaú, o que propiciou a luta comum de toda a população por sua emancipação política, que somente veio a ocorrer em 1983.

O sentimento de pertencimento e apropriação do lugar pelos moradores originais de Maracanaú passou pela vivência desses momentos em comum e se passa ainda por sua lembrança viva.

Pol (1996) defende que a construção da identidade social de uma comunidade está relacionada a um processo de vertebração social que dá sustentação a esse grupo e que pode se produzir a partir de mecanismos de coesão ou identificação e explica:

Nos assentamentos humanos médios e humildes, sem características urbanísticas relevantes, aparece claramente como a identidade social se forja sobre processos de coesão. Somente em assentamentos que possuem características urbanas estruturadas e destacadas, com uma apreciação social positiva, ganha peso a identificação. (p. 54)

O processo de coesão grupal dos moradores foi fundamental para sua permanência na cidade, mesmo após a “avalanche” de estrangeiros ao lugar, como também para a sua permanência na condução política da cidade desde a sua emancipação até 2004, quando o grupo político, oriundo do grupo de moradores originais, perdeu as eleições.

Apesar das transformações vivenciadas na sua relação com o lugar, este grupo de moradores expressa claramente o seu contentamento com o processo de crescimento no qual se inseriu a cidade. Esse fato pode ser compreendido como a superação do mal-estar gerado pelo estigma e o descaso sofridos por seus moradores originais. Hoje, Maracanaú é percebida como uma cidade de futuro, importante e rica. O que leva a uma valorização de si mesmos através da valorização do lugar.

Para os moradores dos conjuntos, a apropriação do lugar passou primeiramente pelo enraizamento (Moles \& Rohmer, 1998) através da casa. Nas entrevistas, estes moradores deixavam claro que o lugar mais importante para eles era a sua casa, mesmo que no início da ocupação dos conjuntos a falta de estrutura de saúde e educação não permitisse uma vivência plena do lugar. Com o passar do tempo e a resolução destes problemas fundamentais, mesmo que não totalmente satisfatória, fez surgir um processo de expansão além dos muros da casa, no qual os moradores dos conjuntos foram ampliando suas interações sociais de vizinhança, constituindo amigos e participando da vida coletiva por meio do envolvimento em diversos tipos de associações. As pessoas que deixaram seus locais de origem e foram morar em Maracanaú aceitaram uma espécie de “inclusão perversa no urbano.” (Peluso, 1997, p. 237); deixaram de viver em áreas urbanas centrais, dotadas de infra-estrutura, para viver em um local, inicialmente, de difícil acesso e sem infra-estrutura, tudo pelo sonho da casa própria. Chegaram ali, entretanto, como colonos com um sonho de vida nova e expressaram muitas expectativas positivas quanto ao futuro da cidade e melhoria da sua qualidade de vida, como também de valorização do seu principal bem: a casa.

O jovem morador de Maracanaú expressa a sua apropriação do lugar sob dois aspectos: identificação simbólica e ação-transformação (Pol, 1996). A identificação simbólica se manifesta através de aspectos afetivos, cognitivos e interativos. O depoimento dos jovens aponta para uma vivência na cidade que contempla estes três aspectos, quando dizem, por exemplo: "Maracanaú é a cidade que amo, ela é minha casa”, que ali estão aprendendo e crescendo, construindo seus projetos pessoais e que é na cidade que estão se relacionando e fazendo amigos. A apropriação forte do lugar vem ocorrendo através de uma vivência ativa, propiciada mais ainda pela facilidade que tem a juventude de interagir com outros jovens do município como um todo. Os relatos falam igualmente de aspectos relacionados com a apropriação por ação-transformação que viria a partir da percepção que tem o sujeito de poder intervir em seu entorno e modificá-lo. Nesse sentido, a ação-transformação se dá a partir da possibilidade de participação cidadã. Eles se dizem preocupados e participantes na vida política do Município. Consideram que podem intervir no seu destino, quando, por exemplo, afirmam que: "respeito e me preocupo com a cidade e quero que ela melhore, cumpro com meus deveres e me sinto cidadão", ou "sinto-me maracanauense porque faço parte da comunidade e luto por sua melhoria”.

Outro ponto fortemente relatado nos discursos é o fato de acreditarem no futuro da cidade. Apostam que ela pode crescer mais e que se tornará um lugar cada vez melhor. Daí, fazem planos para a sua permanência e vivência futura no lugar. Passado, presente e futuro estão representados nos depoimentos dos moradores. O tempo é uma dimensão importante quando relacionada ao espaço. É através do tempo que o sujeito constrói suas experiências e relações, que aprende, vivencia afetos, simboliza, introjeta espaços e constrói sua identidade (Moreno \& Pol, 1999; Lévy-Leboyer, 1980).

Os resultados obtidos com a análise da apropriação levam a pensar na construção da identidade em Maracanaú a partir de vários aspectos: (1) os três grupos de moradores têm se apropriado da cidade com o passar do tempo; entretanto, o fazem de forma diferenciada, tendo em vista sua origem social diversa; (2) a intervenção ocorrida em Maracanaú 
não constituiu uma cidade sem identidade, mas está levando à formação de uma nova identidade; (3) a nova identidade em formação apresenta-se como uma totalidade não homogênea, não idêntica e complexa (Ciampa,1988); (4) A complexidade da identidade manifesta-se nas diversas formas de perceber o entorno físico e social do bairro com relação à cidade, entretanto possui componentes que estão coerentemente relacionados, dando a idéia de uma identidade compartida em nível da cidade como um todo.

A construção da nova e complexa identidade de lugar em Maracanaú pode ser analisada tendo por base os conceitos tratados pela identidade social urbana (Valera \& Pol, 1994). Para que o sujeito se sinta afiliado, pertencente a uma determinada categoria urbana, é necessário que alguns significados sejam socialmente elaborados e compartilhados. Estas significações podem ocorrer com relação a algumas dimensões. São elas: dimensão territorial, social, temporal, de conduta, psicossocial e ideológica.

A dimensão territorial diz respeito à percepção de fazer parte de um determinado território. Em Maracanaú esta dimensão encontra-se fragmentada. Os diversos tipos de moradores se sentem mais ligados ao bairro onde moram, não freqüentam os outros bairros, entretanto, reconhecem a existência da cidade como constituída de vários bairros e um centro ao qual chamam de Maracanaú. Esta toponímia não seria mais representativa da grande cidade de Maracanaú constituída de seu centro histórico e de seus enormes conjuntos e bairros.

Esta mesma forma fragmentada apresenta-se quando se trata das relações sociais. Os discursos falam "do pessoal de um lado e do pessoal do outro lado" referindo-se à falta de interação entre os moradores novos e antigos. Os moradores antigos continuam a viver, em grande parte, nas casas do centro histórico, enquanto os novos ocupam os conjuntos habitacionais. No início da ocupação dos conjuntos, a origem social diferenciada entre os moradores dificultava os contatos. Entretanto, com o passar do tempo, vem ocorrendo uma maior homogeneização dos moradores na cidade e uma maior interação. $\mathrm{O}$ que os moradores expressam com relação à fragmentação social diz respeito à dificuldade de interações em uma grande cidade, onde as relações se dão principalmente com os vizinhos.

De fato, a cidade cresceu muito em pouco tempo e a forma correta de abordá-la é como uma grande cidade. Hoje ela apresenta-se como uma adolescente em crise, não sabe se é grande ou pequena. Os discursos dos moradores falam de uma cidade grande, mas a sua vivência contempla aspectos de cidade pequena: as relações de amizade nos bairros, a proximidade dos serviços essenciais como postos de saúde, escolas e mercados, o fato de terem acesso ao prefeito e aos vereadores sem grandes dificuldades. Da mesma forma falam de uma cidade sem uma forma de cidade, pois não se sabe onde começa ou termina. Estas duas dimensões se expressam confusas quando se trata de considerar o bairro ou a cidade como categorias territoriais. Entretanto, o que se percebe é que a cidade, como um todo, vem sendo apropriada a partir do bairro em que vivem seus moradores. Apesar de vivenciarem mais o bairro, exatamente como fazem os moradores de uma grande cidade, conseguem pensá-la e representá-la, envolvendo aspetos maiores que levam em conta a cidade como um todo, constituindo não somente uma identidade associada ao bairro, mas também à cidade.

Isso se confirma na análise das demais dimensões. Nos discursos de todos os grupos de moradores, percebe-se uma forte ligação com a cidade com relação à dimensão temporal. Os moradores dos conjuntos ou os jovens moradores apontam como lugares importantes da cidade aqueles relacionados com o seu passado, demonstrando assim um conhecimento e valorização destes. O futuro é igualmente tratado por todos com otimismo, o que pode refletir uma disposição de continuidade de vivência na cidade e o fortalecimento das relações com o lugar.

A ligação dos moradores com a cidade se dá no presente por uma vivência ativa dos seus espaços públicos, das suas festas religiosas e tradicionais, ou seja, as condutas relacionadas ao espaço urbano comum são experienciadas pela população como um todo. Igualmente ao que se refere à vivência psicossocial, os diversos grupos de moradores relatam a sua integração em grupos e associações e descrevem a cidade como o lugar onde trabalham, estudam e constituem amigos, sendo este aspecto cada vez mais diluído em todo o município, não se restringindo somente às relações de bairros.

A dimensão ideológica está relacionada à percepção da cidade como uma cidade importante e em crescimento. Todos acreditam em uma melhoria da sua qualidade de vida associada ao lugar.

De uma localidade abandonada e estigmatizada, percebida pelos moradores antigos, passando pela colonização de um território sem infra-estrutura pelos moradores dos conjuntos e da necessidade de mais espaços públicos reclamado pelos jovens, todos alimentam um sonho de vida nova, que é a grande expectativa e a grande motivação dessa nova identidade de lugar ou identidade social urbana em construção na cidade de Maracanaú.

\section{Considerações Finais}

Como qualquer pesquisa, esta discutiu algumas indagações e gerou muitas outras. Alguns aspectos poderiam ser aprofundados em outras pesquisas como, por exemplo: a construção da memória coletiva dos moradores dos conjuntos habitacionais, o estudo das festas e símbolos como expressões da identidade e constituidoras desta, a relação entre participação cidadã e identidade, tendo em vista a existência de diversas associações no município e, principalmente, um estudo sobre qualidade de vida e sua interferência na relação do morador com o lugar.

Este último aspecto se constitui em um ponto fundamental para a aplicabilidade desta pesquisa, que teve, na essência, o objetivo fundamental de dar suporte a ações respeitosas quanto aos diversos moradores da cidade, através de intervenções que promovam qualidade de vida e felicidade. 


\section{Referências}

Centro de Treinamento e Desenvolvimento Regional - CETREDE (1984). Distrito Industrial: fator de expansão urbana. Fortaleza: Autor.

Ciampa, A. da C. (1988). Identidade. In S. T. M. Lane \& W. Codo (Orgs.), Psicologia social: o homem em movimento (pp. 58-75). São Paulo: Brasiliense.

Fischer, G.-N. (1981). La psychosociologie de l'espace. Paris: Presses Universitaries de France.

Halbwachs, M. (1990). A memória coletiva. São Paulo: Vértice.

Instituto Euvaldo Lodi (1983). Avaliação da política industrial do Ceará: uma contribuição ao debate. Fortaleza: Autor.

Jacques, M. das G. C. (1998). Identidade. In M. das G. C. Jacques, M. N. Strey, N. M. G. Bernardes, P. A. Guareschi, S. A. Carlos, \& T. Fonseca (Orgs.), Psicologia social contemporânea (pp. 159-167). Petrópolis: Vozes.

Lévy-Leboyer, C. (1980). Psycologie et environnement. Paris: Presses Universitaries de France.

Moles, A., \& Rohmer, E. (1998). Psychosociologie de l'espace. Paris: L'Harmattan.

Moreno, E., \& Pol, E. (1999). Nociones psicosociales para la intervención y gestión ambiental. Barcelona: Universitat de Barcelona.
Moser, G. (2003). Questionner, analyser et améliorer les relations à l'environnement. In G. Moser \& K. Weiss (Orgs.), Espaces de vie. Aspects de la relation homme-environnement (pp. 11-42). Paris: Armand Colin.

Oliveira, F. de (1977). Elegia para uma re(li)gião: SUDENE, Nordeste, planejamento e conflitos de classes. Rio de Janeiro: Paz e Terra.

Peluso, M. L. (1997). A casa própria e o sonho. In J. B. da Silva, M. C. L. Costa, \& E. W. C. Dantas (Orgs.), A cidade e o urbano: temas para debates (pp. 235-343). Fortaleza: Editora da Universidade Federal do Ceará.

Pol, E. (1996). La apropiación del espacio. In L. Iñiguez \& E. Pol (Orgs.), Cognición, representación y apropiación del espacio (pp. 45-21). Barcelona: Universitat de Barcelona.

Proshansky, H. M., Fabian, A. K., \& Kaminoff, R. (1983). Place-identity: physical world socialization of the self. Journal of Environmental Psychology, 3, 57-83.

Sève, L. (1989). A personalidade em gestação. In P. Silveira \& B. Doray (Orgs.) Elementos para uma teoria marxista da subjetividade (pp. 147-178). São Paulo: Vértice.

Tuan, Y.-F. (1983). Espaço e lugar: a perspectiva da experiência. São Paulo: DIFEL.

Valera, S., \& Pol, E. (1994). El concepto de identidad social urbana: una aproximación entre la Psicología Social y la Psicología Ambiental. Revista Anuario de Psicología, 62, 5-24.

Ada Raquel Teixeira Mourão, mestre em Psicologia pela Universidade de Fortaleza, é doutoranda em Espaço Público e Regeneração Urbana: Arte e Sociedade na Universidade de Barcelona. Endereço para correspondência: Av. Senador Virgílio Távora, 2001, casa 06; Fortaleza, CE; CEP 60.170-251. Tel. (85) 3224-2490. E-mail: adamourao@hotmail.com Sylvia Cavalcante, doutora em Psicologia Ambiental pela Université Louis Pasteur, Strasbourg, França, é professora do mestrado em Psicologia da Universidade de Fortaleza. E-mail: sylviac@unifor.br 